\title{
Estrategias de gestión en la información sobre la monarquía española en un diario digital inglés
}

\section{Information management strategies on the Spanish monarchy in an English digital newspaper}

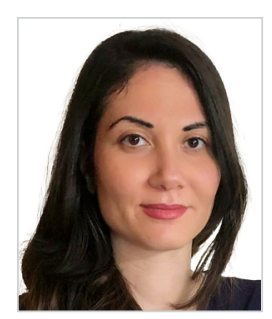

Beatriz Rodríguez Cuadrado. Doctora en Periodismo (UCM). Máster Universitario en Cultura Contemporánea: Literatura, Instituciones Artísticas y Comunicación Cultural por el Instituto Universitario de Investigación Ortega y Gasset y Máster en Formación de Profesorado de Educación Secundaria, Bachillerato, FP e Idiomas (URJC). Ha impartido clases en CEDEU Centro de Estudios Universitarios en materias relacionadas con la comunicación y lengua y cultura española. Ha realizado diversas publicaciones sobre el Análisis del Discurso, la Sociolingüística y el Lenguaje en medios de comunicación en capítulos de libros y revistas relevantes, tanto nacionales como de difusión e impacto internacional, entre las que destacan Revista de Occidente, RILI Revista Internacional de Lingüística Iberoamericana y Revista Comunicación, etc. Ha presentado ponencias en congresos nacionales e internacionales como el celebrado en The London School of Economics and Political Science (SASE) o "el XXXIV Congreso Internacional: «El discurso profesional y académico: una perspectiva interdisciplinar”, organizado por AESLA.

Universidad Europea Miguel de Cervantes, Valladolid, España

brodriguezcu@uemc.es

ORCID: 0000-0002-4207-410X

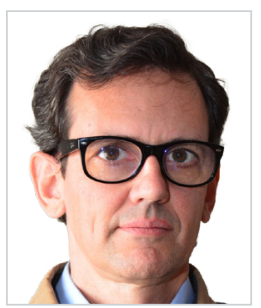

José Antonio Ruiz San Román. Profesor Titular de Sociología y Opinión Pública en la Facultad de Ciencias de la Información. Departamento de Sociología Aplicada. Autor de "Introducción a la tradición clásica de la opinión pública" (Tecnos, 1997) "Sociología de la Comunicación" (Trotta, 1999) e "Investigar en Comunicación. Guía práctica de métodos y técnicas de investigación social en comunicación" (McGraw Hill, 2005). Autor de más de medio centenar de artículos de investigación. Profesor visitante en Stanford University (1999) y en el Institute of Communications Research de la Universidad de Illinois (2011). Coordinador del Máster de Estudios Avanzados en Comunicación Política de la Universidad Complutense de Madrid (2013-2015) Responsable Prácticas Externas de la Facultad de Ciencias de la Información (2016-2017). Vicedecano de Relaciones Institucionales, Movilidad y Prácticas de la Facultad de Ciencias de la Información desde junio de 2017.

Universidad Complutense de Madrid, España

jars@ucm.es

ORCID: 0000-0003-3161-0330

Cómo citar este artículo:

Rodríguez Cuadrado, B y Ruiz San Román, J. A. (2021). Estrategias de gestión en la información sobre la monarquía española en un diario digital inglés. Doxa Comunicación, 32, pp. 41-55. 
Recibido: 21/03/2020 - Aceptado: 17/02/2021 - En edición: 30/04/2021 - Publicado: 14/06/2021

\section{Resumen:}

Este trabajo se ocupa de uno de los modos sutiles de presentar informaciones sesgadas. Se estudian las estrategias discursivas empleadas por The Guardian para informar sobre la monarquía española en un momento crítico para esta, la etapa en la que tiene lugar la abdicación del rey Juan Carlos I. Se utiliza el análisis del discurso basado en la teoría de la (des)cortesía (Brown y Levinson, 1987). El corpus está constituido por todas las noticias sobre la monarquía española que tienen en su titular las palabras Spain o Spanish durante los años 2013 y 2014 y que aparecieron en la versión digital de este diario inglés. Algunas de las noticias se analizan con mayor detalle en función de su relevancia. Los resultados muestran cómo el diario británico usa distintos mecanismos discursivos, entre ellos la insinuación, la metáfora, la simbología o las referencias al mundo literario shakespeariano, que contribuyen a formar una imagen distorsionada de la realidad.

Palabras clave:

Monarquía; noticias falsas; desinformación; medios de comunicación; lenguaje, Reino Unido; opinión pública; The Guardian.
Received: 21/03/2020 - Accepted: 17/02/2021 - Early access: 30/04/2021 - Published: 14/06/2021

Abstract:

This paper approaches one of the subtle ways of presenting biased information. It analyses the discursive strategies employed by The Guardian to inform about the Spanish monarchy at a critical moment, the period in which the abdication of King Juan Carlos I took place. The discourse analysis is used based on the impoliteness theory (Brown and Levinson, 1987). The corpus includes all the news about the Spanish monarchy that have in its headline the words Spain or Spanish during the years 2013 and 2014 and that appeared in the digital version of this English newspaper. Some of the news are analysed in greater detail depending on their relevance. The results showed how the British newspaper uses different discursive mechanisms, including insinuation, metaphor, symbology or references to the Shakespearean literary world, which contribute to a distorted image of reality.

Keywords:

Monarchy; fake news; misinformation; media; language; United Kingdom; public opinion; The Guardian.

\section{Introducción}

Fenómenos como las noticias falsas y la desinformación pueden tener una repercusión negativa en la reputación de una institución, e incluso contribuir al desencadenamiento de determinados hechos de relevancia histórica. Esta cuestión no es nueva. Diversos estudios (Cabrera González y Ruiz San Román, 2007; Burgueño, 2019) señalan que las noticias falsas se llevan empleando durante siglos "en períodos bélicos o para justificar decisiones difíciles", por parte de cualquier esfera de poder (Burgueño, 2019). Asimismo, a través de estos fenómenos es posible realizar una campaña de descrédito para conseguir un determinado fin. Rodríguez Cuadrado (2019) manifiesta que esta nueva corriente, que se produce de forma deliberada, hace reformular la teoría comunicativa de la agenda setting. El primer nivel de la teoría de la agenda setting hace referencia a que los medios de comunicación deciden sobre qué pensará la audiencia y en el segundo nivel, los medios decidirían lo qué pensará la audiencia (McCombs, 1994). Planteamos la necesidad de repensar la teoría con ocasión de la irrupción del periodismo transmedia en el que el lector adquiere mayor protagonismo, interactúa y participa en la generación de contenido. Todo ello en un entorno de saturación de información, lo que supone que la audiencia se vea en ocasiones ante la necesidad de contrastar y evaluar la veracidad de esta.

La salida del Reino Unido de la Unión Europea en febrero de 2020 va intrínsecamente asociada al concepto del rechazo. En este escenario de desintegración, es oportuno reflexionar sobre las implicaciones que los textos periodísticos han tenido en los años previos para incrementar o mitigar este rechazo. Aún no conocemos las repercusiones reales del Brexit, 
sin embargo, sí sería posible analizar qué factores pudieron determinar la opinión pública para querer desvincularse de esta institución y de los países que la conforman.

La cobertura y el tratamiento informativo repercute, en mayor o menor medida, en la imagen de un país. La salida del Reino Unido se ha estado fraguando de una forma paulatina a lo largo del tiempo. Ya en el año 2013, el primer ministro David Cameron hizo la promesa de que si ganaba las elecciones que se celebrarían dos años más tarde, convocaría un referéndum sobre la permanencia en la Unión Europea antes de finalizar su mandato. (http://www.gov.uk/government/ speeches / eu-speech-at-blomberg).

Esta investigación se centra en años en que aparecen problemas importantes que afectan a la imagen de la monarquía española. Esta institución no ha sido estudiada suficientemente desde el punto de vista académico como organización generadora de una imagen de España en el exterior que puede llegar a influir en los sectores económico, político y social del país. Como pone de manifiesto Barredo Ibáñez, informar sobre la monarquía en los medios españoles no es una tarea fácil (2013:3): "La monarquía española es uno de los entornos informativos más restrictivos para los periodistas de la democracia actual”. Igualmente, este autor (2013:2) entiende que los medios de comunicación: "son, ante todo, los constructores de los significados simbólicos en los que se sustenta su reputación". El fundamento de este tipo de ideas ha influenciado la intención de este estudio por investigar sobre un medio de prensa extranjero de un país que a su vez tiene en común con España esta institución.

Alonso Benito (2014) se hacía eco del desgaste de la imagen de la monarquía en la opinión de los españoles:

La mala imagen de la clase política es realmente llamativa, y junto a ella se ha instalado una visión muy negativa de la institución más protegida por la cultura de la Transición, la monarquía, en la que el deterioro físico del monarca y diversos escándalos han llevado a que esta institución aparezca suspendida en los últimos años por su valoración ciudadana (...) (Alonso Benito, 2014:10).

Asimismo, este autor sostiene que:

a principios de 2014, son muchas las voces que ya alertan que estamos ante un fin de ciclo. Los datos demoscópicos parecen señalarlo con vehemencia: los principales actores en el desarrollo de la democracia española en estas décadas, los representantes políticos y la monarquía, se encuentran hundidos en las encuestas (Alonso Benito, 2014:10).

El objeto de estudio de esta investigación ha sido el análisis del tratamiento periodístico de The Guardian sobre la Casa Real Española durante los años 2013 y 2014. Se ha seleccionado esta franja temporal ya que coincide con el momento álgido de la crisis socioeconómica y de valores que ha padecido el mundo occidental. En el año 2013 las cifras sobre el desempleo alcanzaron su máximo (Fuente: Encuesta de Población Activa, 2013); España sufría los peores momentos de la crisis. La decadencia de la monarquía española va en paralelo a esta crisis, que afecta a todos sectores del país. Es en el año 2014 cuando tiene lugar el inicio de la recuperación económica. Asimismo, si el primer año coincide con un momento de decadencia de la monarquía, en el segundo año se produce la abdicación del rey. De ahí que se haya partido de las manifestaciones del lenguaje y la interpretación de su significado en el contexto, centrándonos en los mecanismos lingüísticos empleados por los medios de comunicación. 
Desde el año 2013, este diario apostó por la versión web del Guardian Australia, lo que supone la difusión y el alcance a más lectores. En los años objeto de estudio, The Guardian ganó numerosos premios de prestigio nacional e internacional: Newspaper Awards, por el que fue nombrado servicio de noticias digitales del año (2013); Press Awards como mejor diario del año (2014); Premio Pulitzer, compartido con The Washington Post (2014). Durante estos dos años, también fue premiado por la Society for News Design.

Es preciso subrayar que el objetivo de este estudio es mostrar cómo la prensa puede reflejar, bajo la apariencia de un relato periodístico literariamente atractivo, una imagen deliberadamente inexacta de una institución mediante estrategias discursivas sutiles que determinen negativamente la opinión de sus lectores. Sin embargo, sobre su repercusión, es necesario tener en cuenta que la falta de veracidad en las noticias es solo una pieza de un entramado complejo, generalmente combinado con información verdadera. En este estudio, no se insertan consideraciones sobre la actuación de la monarquía, sino sobre cómo gestiona un medio de comunicación el tratamiento de la información sobre la propia monarquía.

En nuestro trabajo hemos optado por seguir los estudios sobre la cortesía (Lakoff, 1973, Leech, 1983, Brown y Levinson, 1987). La necesidad de captar la atención de la audiencia hace que el periodista juegue, en ocasiones, con las estrategias de la cortesía lingüística, o incluso las incumpla deliberadamente.

El empleo de este tipo de recursos lingüísticos por parte de los medios permite reducir las posibilidades de que la noticia suponga un "acto de amenaza directa" (face threating act) (Brown y Levinson, 1987) contra la imagen pública (Goffman, 1967). Estos autores afirman que un hablante $(\mathrm{H})$ puede emitir enunciados que afectan la imagen del oyente (O), pero para mitigarlos se puede servir de atenuadores (Brown y Levinson,1987). Gil profundiza sobre esta teoría y señala (2006:78): "Los actos de habla no-descorteses son los actos de habla amenazadores de imagen (AAI), mientras que los actos de habla descorteses son los invasores de imagen (AII)". En este contexto, no podemos dejar de tener en cuenta dos factores de gran relevancia, como son la distancia social y las relaciones de poder (Brown y Levinson, 1987). Estos autores mantienen que la cortesía se emplea como elemento mitigador antes los actos que amenazan la imagen pública. Para medir su grado crearon la siguiente ecuación: $\mathrm{Wx}=\mathrm{D}(\mathrm{S}, \mathrm{H})+\mathrm{P}(\mathrm{H}, \mathrm{S})+\mathrm{Rx}$. (w= weightiness, $\mathrm{D}=$ distance, $\mathrm{S}=$ speaker, $\mathrm{H}=$ hearer, $\mathrm{P}=$ power, $\mathrm{R}=$ rank). Carrasco Santana (1999:10) explica que: "el grado de potencial amenaza de un acto (W) dependerá de la distancia social (D) que exista entre el emisor (S) y el receptor (U), de la relación de poder (P) entre ellos, y del propio grado de imposición del acto (R)en cuestión".

Estos conceptos, tomados del campo de la lingüística, son extrapolables a la comunicación periodística. Así, el emisor es el periodista que publica en el diario, el receptor sus lectores.

En este trabajo se presentará un análisis de la noticia King Juan Carlos of Spain: a fairytale told by politicians, (Theguardian.com, 6/04/2013) bajo el supuesto de que su discurso puede influir en la creación de un marco de pensamiento para los lectores. Este caso hace uso de la simbología shakespeariana (muy familiar para los lectores anglosajones) con la finalidad de vincular esa simbología a la situación de la monarquía española.

Como es sabido, la desinformación se produce no solo a través de las noticias falsas, también con la información ambigua o incluso a través de la insinuación, de los silencios, de la selección de los contenidos, de su ordenación, etc. La "distorsión informativa" cuando es sutil, pretende también confundir al público y se convierte en herramienta invisible y, a la vez, 
poderosa. Badillo (2019:6) reflexiona sobre el dominio ejercido por los medios: "Ese debate entre el poder de los medios para imponer significados y el poder de los individuos para descodificarlos ha marcado la discusión sobre este asunto en las ciencias sociales de las últimas décadas".

García Inda (2019) reflexiona sobre las noticias falsas y señala:

Su capacidad de corromper la información y el verdadero conocimiento (...) donde se mezclan hechos y opiniones, y la argumentación crítica y el debate de ideas son suplantados por la fanfarronería, la especulación y el insulto. Con otras palabras, la presunta democratización de la verdad - y digo presunta porque hablar de 'verdad democrática' seguramente es un oxímoron para ocultar o disfrazar la ausencia o deformación de la verdad.

Es destacable el planteamiento de este autor acerca de la información desfasada como otra estrategia de la manipulación y, por tanto, de la desinformación. García Inda (2019) advierte así de sus diferentes manifestaciones: “Ciertamente, la manipulación informativa no estriba únicamente en hacer pasar lo falso por verdadero, sino también lo pasado por actual, o lo común por inusual y novedoso". (García Inda, A. (2019). "Fakes". El Heraldo. Disponible en bit.ly/2mO2ExP)

Para Vilarroya (2019) las fake news no son más que relatos que se nutren de situaciones de miedo y de ira y cuyo fin es manipular y engañar. En consonancia con lo anterior, en la presente investigación ahondamos en un ejemplo muy significativo, la noticia como relato a través del mundo literario. En este caso, estamos ante el planteamiento del problema ("la crisis de la monarquía") a través de paralelismos literarios como mecanismo la difusión de inexactitudes históricas.

Sin embargo, como manifiestan Cabrera González y Ruiz San Román (2007), la pérdida de credibilidad no es lo más grave (2007:117): "lo más aterrador vendría de la mano de la espiral de daños que una falsedad puede desencadenar". Sobre ello, expresan que para frenar esta escalada de falsedades se debe tener en cuenta la reflexión de Sullivan (2003) acerca de que la mentira es un vicio que se difunde ampliamente a través de una historia, la mitología o las anécdotas deformadas.

Además del marco de las investigaciones sobre noticias falsas, este trabajo, como se ha mencionado anteriormente, se apoya en los estudios sobre los fundamentos teóricos de la cortesía lingüística, considerada como un fenómeno sociopragmático que determina el éxito o el fracaso del proceso comunicativo entre un emisor y un receptor. El estudio del concepto de cortesía lingüística fue inicialmente abordado por Lakoff (1973), basado a su vez en las máximas conversacionales de Grice (1975) que atienden a la eficacia de un acto comunicativo. Posteriormente, Brown y Levinson (1987) desarrollaron el modelo de cortesía (politeness) basado en el concepto de imagen pública (Goffman, 1967) que se ofrece al receptor del mensaje. En este estudio, consideramos que es posible aplicar esta teoría también a un organismo, una institución o un país. Estos autores plantean una serie de estrategias para dotar a los interlocutores de unos instrumentos o recursos capaces de paliar la necesidad de los individuos de preservar su imagen cuando esta se ve amenazada mediante un acto del habla (face threating act). Por el contrario, algunos actos del habla son empleados para crear una amenaza de manera deliberada. Sería entonces posible hablar de una teoría de la descortesía (Watts, 2008; Fuentes Rodríguez, 2009; Alcaide Lara, 2010).

Entre los antecedentes, se encuentra la visión lingüística de Austin (1962) que relaciona las palabras con las acciones, es decir, la propia caracterización de las palabras condiciona la eficacia del acto comunicativo. De esta manera, en el planteamiento de esta teoría convergen el significado, "la fuerza ilocutiva" (entendida como intención comunicativa) y "los 
efectos perlocutivos". La complejidad lingüística de la teoría austiniana reside en que en el acto de habla no existe una acción lingüística sin una intención comunicativa.

Sin embargo, la aportación que mayor influencia ha generado fue la realizada por Brown y Levinson (1987). Estos autores desarrollan una serie de estrategias que relacionan la implicatura con esta teoría, basadas fundamentalmente en la Máxima de la Relevancia de Grice (1975). Las estrategias parten de la idea de que la violación deliberada de la relevancia constituye una forma de que el receptor del mensaje capte la intención del emisor. Sobre estas estrategias "encubiertas", Brown y Levinson (1987) mantienen que son las más extendidas en las interacciones sociales. Así, algunas de las que consideramos que podrían considerarse aplicables al análisis de la (des)cortesía en el discurso periodístico se exponen a continuación: proporcionar asociaciones, emplear contradicciones, ser irónico, usar metáforas, usar tautologías, hacer preguntas retóricas, ser ambiguo, ser impreciso, generalizar y no proporcionar la totalidad de la información (Brown y Levinson, 1987).

El estudio del fenómeno del eufemismo y el disfemismo (Casas Gómez, 1986, Díaz Pérez, 2012) están vinculados con los estudios sobre semántica y tiene una larga tradición anterior a la teoría de la cortesía lingüística. El uso de eufemismos en los medios de comunicación está impulsado por el deseo de evitar conflictos comunicativos, así como de promover y fijar ciertas ideas sobre la sociedad (Sadovnikova et al., 2016).

Por otra parte, se ha llegado a emplear asociado a la descortesía el término "grosería" entendido como "una desviación de aquello que se entiende como cortés en un contexto social, es de enfrentamiento inherente y perjudicial para el equilibrio social" (Yus, 2010:284).

Finalmente, existen estudios sobre el tratamiento de la cortesía en el ámbito publicitario (Saz Rubio, 2000; Alcoba y Poch, 2011), sin embargo, existen muchos menos trabajos enfocados al tratamiento de la (des)cortesía en el discurso periodístico digital. Hay estudios que señalan que la función principal de la (des)cortesía en publicidad es reparadora, es decir, sigue las siguientes fases: Destrucción-reparación virtual y actuación (Alcoba y Poch, 2011:33).

\section{Metodología}

Antes de exponer la metodología de este trabajo, es necesario subrayar que, para explicar la inclusión de la temática de la monarquía española en la agenda del periódico inglés, podemos acudir al prestigio que la organización monárquica tiene en la idiosincrasia británica. Otra razón que puede justificar este interés es la de, según palabras de este medio británico, los “escándalos" producidos dentro de la familia real española en este periodo de tiempo.

En cuanto a la elección de este diario, esta se debe a que The Guardian con el tiempo ha conseguido consolidarse como un periódico de gran notoriedad más allá de sus fronteras. Asimismo, es uno de los diarios que más tráfico digital atrae del mundo. Los datos aportados muestran la amplia cobertura de su versión digital (Fuente: comScore). En el mes de mayo de 2013 se convirtió en el sitio web de periódicos más popular del Reino Unido, alcanzando 8,2 millones de visitantes únicos por mes. Este diario, según esta misma fuente, en el 2014 se convirtió en el segundo diario digital más popular en lengua inglesa, con 42,6 millones de usuarios únicos en septiembre frente a los 41,6 millones de usuarios del New York Times. 
El corpus textual seleccionado está compuesto por las noticias publicadas sobre España en la edición digital del periódico mencionado. Este corpus está constituido por 122.143 palabras distribuidas en 216 noticias (incluidas todas las temáticas y secciones a excepción de los deportes). Para su composición se extrajeron aquellas que presentaban en el titular las palabras Spain y Spanish. Una vez obtenido, para este estudio se extrajeron aquellas cuya temática era exclusivamente la monarquía española (15 noticias).

Esta investigación está estructurada en dos partes. La primera la constituye un análisis automático que ofrece los datos cuantitativos relativos a la frecuencia léxica. Estos han sido extraídos a través de la herramienta textual Sketch Engine, que además nos ha proporcionado información a diferentes niveles, como el gramatical y el léxico-semántico. Esta herramienta nos ha permitido realizar un tratamiento informático de los datos gracias a las funciones de las que dispone. Una de ellas permite opciones para buscar el número de apariciones de las palabras del corpus; una segunda función proporciona un análisis sobre las colocaciones gramaticales y léxicas de una palabra. Desde la función léxico-semántica, ha sido posible obtener datos sobre la frecuencia, concordancias, constelaciones de palabras, etc. de los términos analizados. De esta forma, en esta investigación nos hemos centrado en las palabras que pudieran proporcionar aspectos positivos o negativos asociados a la institución monárquica y en el análisis posterior del discurso.

Tras el análisis automático y para reforzar la validez de este estudio, se procedió a la segunda fase cualitativa de carácter manual. Para ello, se llevó a cabo una lectura pormenorizada de todas las noticias publicadas durante el periodo objeto de estudio sobre la monarquía. A continuación, se buscaron las connotaciones y denotaciones positivas o negativas sobre esta.

Por último, a raíz de la lectura pormenorizada se halló una noticia muy significativa que ilustra el poder de los medios a través del lenguaje. Por tanto, se proporciona con este ejemplo un estudio de caso que se considera relevante por el empleo de elementos persuasivos que se presentan mitigados a través de diferentes técnicas del lenguaje. Se ofrece de esta noticia un análisis léxico e interpretativo para hallar el significado que posee para la imagen de la institución monárquica.

\section{Resultados}

Con respecto al análisis cuantitativo realizado en la primera fase de este estudio, en los años 2013 y 2014 se hallaron 15 noticias en cuyos titulares aparece España y la monarquía española. Estas se presentan a continuación:

1. Spain's Princess Christina named as suspect in corruption case (3/04/2013).

2. King Juan Carlos of Spain: a fairytale told by politicians (6/04/2013).

3. Spanish taxes pay for King Juan Carlos to go from have-yacht to have-not (18/11/2013).

4. Spain's Princess Cristina in court over tax fraud claims (7/1/2014).

5. Spain's King Juan Carlos to abdicate (2/04/2014).

6. King Juan Carlos's reign in Spain ends amid falling popularity and bungling (2/06/2014).

7. Juan Carlos abdication sparks calls for referendum on Spain's monarchy (2/06/2014). 
8. Crown Prince Felipe: the man who will be king of Spain (2/06/2014).

9. Spanish activists launch street referendum over future of monarchy (13/06/2014).

10. Spanish king and queen to retain titles and immunity after abdication (18/06/2014).

11. Spain's Felipe VI promises a 'renewed monarchy' as he is sworn in as King (19/06/2014).

12. Princess Cristina corruption case in Spain is given go-ahead (25/06/2014).

13. Princess Cristina fraud case leads to calls to strip her name from Spain's Streets (3/08/2014).

14. Spanish king's sister faces trial after court approves tax fraud charges (7/11/2014).

15. Spanish king's sister to stand trial on tax fraud charges (22/12/2014).

Con respecto a las fechas de publicación, se observa que únicamente se han hallado tres noticias a lo largo del año 2013 y consecuentemente se han encontrado 12 noticias en el siguiente año. Este aumento cuantitativo se asocia a la abdicación del rey Juan Carlos I que fue anunciada el 2 de junio de 2014 y se hizo efectiva el 19 de junio de ese mismo año.

Si bien el número de noticias no es elevado, por momentos encontramos una notable cobertura. Por ejemplo, las 7 noticias (desde el 2 junio de 2014 hasta 25 de junio de 2014) son suficientes por su relevancia y para el análisis que se propone.

Los temas tratados son relativos principalmente a la corrupción que se imputa a determinados miembros de la Familia Real y a la abdicación del rey. A continuación, se presentan los datos relativos a la frecuencia (ordenados de mayor a menor) que nos ofrecen información sobre la cobertura que se dedica a los diferentes miembros de la familia real.

El nombre de la infanta Cristina aparece en primer lugar en frecuencia con 65 casos; seguido por el de Felipe, que aparece en 59 ocasiones; posteriormente, le sigue el nombre del rey Juan Carlos que aparece en 54 casos; finalmente se ha hallado el nombre del marido de la infanta Cristina, Iñaqui Urdangarin, que aparece en 31 ocasiones.

Una vez mencionados los nombres propios, se presentan tres términos clave para esta temática: la palabra monarchyque aparece en 49 ocasiones y las palabras abdicate y abdication que aparecen en 33 ocasiones.

Cabe destacar que en concordancia con Spain se ha encontrado la monarquía asociada a términos como el escándalo, la corrupción, el blanqueo de dinero y la evasión de impuestos. Casi todos ellos están vinculados al caso de la infanta Cristina y su marido, Iñaki Urdangarin. Los restantes se refieren a la crisis monárquica que culmina con la abdicación del rey Juan Carlos.

A continuación, se expondrán algunos ejemplos del tratamiento de la información sobre la Casa Real española. Así, un caso se presenta en el siguiente extracto como muestra manifiesta de la caída de la popularidad del monarca emérito: "King Juan Carlos's reign in Spain ends amid falling popularity and bungling". Sin embargo, posteriormente, se publican noticias más optimistas cuando se refieren a la abdicación del rey Juan Carlos y al discurso del nuevo rey, Felipe VI, como se puede apreciar en los siguientes fragmentos dentro del cuerpo de diferentes noticias:

1. "the best moment for change".

2. "my faith in the unity of Spain". 
3. "In a unified and diverse Spain, based on the equality of and solidarity between its people".

4. "the new king of Spain, he vowed to move the monarchy away from its scandal-plagued past".

5. "he gave those up and helped steer Spain into a remarkable and relatively peaceful period of transition that allowed the country to join the democratic world".

No obstante, en el ejemplo número 4 podemos observar que el optimismo al que hacíamos referencia se ve atenuado por la metáfora contenida en "scandal-plagued past".

En algunos artículos se ha hallado una explícita intención por informar positivamente sobre el pasado del futuro rey Felipe VI. Este hecho es posible observarlo en los siguientes enunciados, tomados de la noticia Crown Prince Felipe: the man who will be king of Spain (Theguardian.com, 2/06/2014):

- Nearly two-thirds of Spaniards said last year that they believed it was time for the king to abdicate, suggesting that many see Felipe as the monarchy's best hope of moving forward (Traducción: Casi dos tercios de los españoles dijeron el año pasado que creían que era hora de que el rey abdicara, lo que sugiere que muchos ven a Felipe como la mejor esperanza de la monarquía para avanzar).

- Fluent in English, French and Catalan along with Spanish, Felipe studied for a year in Canada before undertaking three years of military training in Spain's armed forces academy. A law degree in Madrid soon followed, as well as a master's in international relations from Georgetown University in Washington, DC. (Traducción: Habla con fluidez en inglés, francés y catalán junto con el español, Felipe estudió durante un año en Canadá antes de emprender tres años de entrenamiento militar en la academia de las fuerzas armadas de España. Pronto obtuvo una licenciatura en derecho en Madrid, así como una maestría en relaciones internacionales de la Universidad de Georgetown en Washington, DC).

- His low-key image was bolstered by his marriage to a commoner in 2004 (Traducción: Su imagen discreta fue reforzada por su matrimonio con una plebeya en 2004).

- He has promoted more openness and transparency for the monarchy, while carefully avoiding being seen in public with his sister Cristina, who along with her husband Iñaki Urdangarin is embroiled in a long-running corruption scandal. Instead, Felipe and his wife have focused their attention on taking over an increasing number of public functions from his father, including Spain's most recent National Day celebrations. (Traducción: Ha promovido más apertura y transparencia para la monarquía, evitando cuidadosamente ser visto en público con su hermana Cristina, quien junto con su esposo Iñaki Urdangarin está envuelto en un escándalo de corrupción de larga duración. En cambio, Felipe y su esposa han centrado su atención en hacerse cargo de un número cada vez mayor de funciones públicas de su padre, incluidas las celebraciones más recientes del Día Nacional de España).

Tal y como se ha descrito en páginas anteriores, se analiza la noticia "King Juan Carlos of Spain: a fairytale told by politicians", (Theguardian.com, 6/04/2013). Esta noticia mantiene la tesis de que la monarquía española se legitima asentándose a través de símbolos, metáforas y analogías, lo cual paradójicamente la deslegitima. 
La primera estrategia lingüística que se puede observar es el eufemismo que contiene la palabra "fairytale" contenida en el titular. Tal como define MerriamWebster.com, esta palabra en su forma adjetival significa: "characteristic of or suitable to a fairy tale, especially: marked by seemingly unreal beauty, perfection, luch, or happiness".

El discurso continúa con una analogía que el periodista construye a través de referencias a los grandes dramas del universo shakesperiano (Rodríguez Cuadrado, 2017), que en nada pueden calificarse como cuentos de hadas. Como sostienen Hernández Corchete y Gómez Baceiredo (2010:66): "La fábula es una narración ficticia que se emplea con frecuencia como estrategia retórica en todos los géneros tradicionalmente considerados «de opinión» (...)”. Estos autores consideran que su finalidad reside en emitir un juicio moral de la actuación de los profesionales de la política. En el ejemplo analizado se presenta una "valoración" del comportamiento de la Familia real.

- The Spanish monarchy's legitimacy was based on symbols, metaphors and, first and foremost, on storytelling. Se ignora por tanto que la elección de nuestra monarquía sea democrática al ser apoyada como forma de Estado en el referéndum de 1978. Además, este concepto se ve reforzado más adelante cuando dice "La monarquía española nació fuera y por encima de la ley". La implicatura es que la monarquía española es ilegítima, por tanto, se trata de una "información falsa encubierta".

La insinuación de la puesta en duda de la legitimidad de la Corona que se lleva a cabo supone un acto del habla que amenaza su imagen pública. La primera observación del enfoque adoptado refleja que se está produciendo un claro acto de amenaza contra la imagen de la monarquía española; sin embargo, simultáneamente se está elevando a los miembros de la realeza española, al situarlos en el mismo nivel que los grandes reyes de las obras de Shakespeare. Estaríamos ante un fenómeno de compensación (En Rodríguez Cuadrado, 2017).

A continuación, se exponen ejemplos de una metáfora y varias analogías del mundo shakespeariano:

- King Juan Carlos of Spain must be one of the most Shakespearian kings, ever. His grandfather was ousted from the throne like Richard II, and like Richard III, his brother was killed (though in Carlos' case it was a tragic accident) (Traducción: El rey Juan Carlos de España es sin duda uno de los reyes más shakeasperianos que jamás haya existido. Su abuelo fue destronado como lo fue Ricardo II y como Ricardo III, su hermano fue asesinado (aunque en el caso de Carlos fue un trágico accidente).

En la primera frase, hallamos una metáfora en la que se identifica al rey español con uno de los reyes más shakesperianos. A continuación, encontramos dos analogías, la primera con Ricardo II y la segunda con Ricardo III. Las insinuaciones o implicaturas que podemos vislumbrar tras esta figura del lenguaje son de extrema gravedad, al tratarse este último de un personaje siniestro. Explícitamente la única analogía que podemos hallar en la realidad entre Ricardo III y el rey Juan Carlos es la muerte accidental de su hermano. Sin embargo, es imposible evitar todas las asociaciones que esta analogía suscita. La figura de Ricardo III, entre literaria e histórica, es conocida como un sangriento tirano. Su figura fue retratada por Shakespeare como un personaje tullido, con malformaciones de nacimiento. Además, pasó a la historia como el asesino de los hijos de su hermano y tras la muerte de este, accedió al trono de esta manera con ese estigma. También, en este caso, en el texto, encontramos otra inexactitud ya que el hermano de Ricardo III (Eduardo IV) no fue asesinado, sino que en realidad murió por enfermedad. 
- Like Hamlet he had a difficult relationship with his father, and like Macbeth, he arrived at the crown by way of an evil creature (General Franco) (Traducción: como Hamlet, tuvo una difícil relación con su padre y como Macbeth, llegó a la corona por medio de una criatura del mal (General Franco)).

A pesar de que el autor crea una analogía con el príncipe de Dinamarca, esta es difícil de hallar, ya que Hamlet lo que pretendió fue vengar la muerte de su padre a manos de su tío. A Hamlet se le encomienda cumplir la consigna del fantasma de su padre de vengar su muerte. Por tanto, no implica una relación difícil con él. En la noticia se crea una confusión. Si la analogía se hubiera establecido con su tío y padrastro, se hubiera acercado más a la realidad.

Con respecto a la segunda analogía del párrafo, Macbeth es un personaje que simboliza la ambición. Los otros temas principales de este drama, como la culpa y el destino, tratan en torno a esta y sus consecuencias. Shakespeare usa imágenes y simbolismo para ilustrarlos. La ambición de Macbeth le conduce a su trágico destino. Desprovisto de cualquier moralidad, Macbeth se siente protegido de cierta forma, incluso invencible. Además, la lady Macbeth shakesperiana es una dama perversa que tienta a su ambicioso marido para que siembre la muerte y la desgracia a su alrededor para escalar socialmente. Macbeth es un personaje que intenta escapar de la culpabilidad por la ilegitimidad de su ascenso al trono. Hallamos en este párrafo la metáfora "evil creature". Este enunciado constituye un acto de amenaza directo, sin ningún tipo de atenuación ni ambigüedad, hacia la figura de Franco.

- It sounds inevitable that, like King Lear, in his old age he would be cursed with troublesome daughters. Now, one of them, Princess Cristina, has been summoned by a judge. (Traducción: Parece inevitable que, como el rey Lear, en su vejez ha sido maldecido con una hija problemática. Ahora una de ellas, la Infanta Cristina, ha sido citada por el juez).

Sin embargo, esta similitud que podría haber sido desarrollada al existir más paralelismos, se centra únicamente en la supuesta apropiación indebida de millones de euros por parte de la infanta y su marido.

Otras observaciones del texto:

El periodista proporciona un enunciado que requiere una justificación que en el texto no aparece.

"Se nos dijo que el rey había traído la democracia a España. (...) Se nos dijo que los republicanos también le querían. (...) Como en todos los cuentos, hay algo de realidad en esta ficción. El rey contribuyó a la transición democrática y se enfrentó al golpe militar de 1981" (Traducción de los autores),

Sin embargo, el periodista informa de que el rey se vio movido a hacerlo, ya que era la única alternativa si quería reinar.

“Como el teatro, la monarquía había comenzado como un culto religioso y terminó en un espectáculo popular. Eso fue todo. En sistemas estables como el Reino Unido, esta transición del arte de gobernar al arte escénico se podía hacer más o menos eficazmente, pero en España el truco se lleva demasiado lejos.” (Traducción de los autores).

Los recursos estilísticos más significativos desde el punto de vista del discurso periodístico son la metáfora y la hipérbole, que nos llevan a la presentación de una visión desvirtuada que se acerca en ocasiones a las denominadas fake news.

Con respecto al nivel de amenaza contra la imagen de la monarquía, lo indica la ecuación de Brown y Levinson (1987) antes mencionada, teniendo en cuenta la distancia social entre esta y el medio. La correspondencia sería: Speaker = el autor de la noticia, Hearer = la monarquía, y R (o grado de imposición del acto)= el grado de difusión de la noticia. 


\section{Discusión y conclusiones}

La cobertura ofrecida sobre la monarquía en el diario The Guardian y la manera de informar manifiesta propósitos subyacentes. El deterioro de la imagen de la monarquía durante la última etapa del reinado de Juan Carlos I es un tema relevante en España. Sin embargo, la información que ofrece este medio, con informaciones sutilmente sesgadas, podrían buscar hacer llegar a los lectores una determinada opinión. La cuestión está en reflexionar sobre si se ha destinado a las noticias la relevancia que realmente tienen para los británicos.

Es posible afirmar que en la noticia que juega con las referencias a la obra shakespeariana, los estereotipos se vinculan con la base cultural de los esquemas y modelos mentales de los lectores (Rodríguez Cuadrado, 2017). La teoría de la (des) cortesía también se ha hallado en el estilo adoptado en la noticia, a través de las metáforas y el estilo literario, así como en actos del habla que suponen amenazas directas. A través de referencias literarias universales, se ha conseguido mitigar actos que amenazan a la imagen (face threating act) de la monarquía española, algo que no hubiera ocurrido si se llega a emplear un lenguaje directo. Por tanto, en este análisis pormenorizado se han evidenciado que gran parte de las analogías creadas por el periodista contienen imprecisiones, alusiones falsas o erróneas. Así, estamos ante afirmaciones que, valiéndose de inexactitudes para establecer una analogía difícilmente sostenible. El discurso y las técnicas empleadas por el periodista de The Guardian, Miguel-Anxo Murado, le sirven para evitar una confrontación directa entre el periódico y la Casa Real Española.

Las inexactitudes, errores históricos e insinuaciones periodísticas en The Guardian que mostramos en este texto contribuyen a forjar una imagen negativa sobre la monarquía española que, en aquel momento, se mostraba particularmente vulnerable. La generalización de un tratamiento paralelo en la prensa europea en el que no se observan las normas de cortesía relativas a la imagen pública (Brown y Levinson, 1987), pudo haber contribuido a generar un marco propicio también en el exterior para la abdicación del rey Juan Carlos en el año 2014 y para el desprestigio de la institución monárquica.

Sin embargo, se observa que, una vez producida la abdicación del rey emérito en el año 2014, este diario informa de la figura de Felipe VI, ofreciendo datos que presentan al nuevo rey como una persona formada y preparada para el cargo que va a desempeñar.

La reiteración de unas determinadas estrategias lingüísticas (como la analogía, la metáfora o el eufemismo) pone de manifiesto el uso de la teoría de la cortesía por parte los medios de comunicación. Desde este punto de vista, es destacable la agudeza y la creatividad del periodista que implica dotar al discurso de mayor fuerza, y, en definitiva, captar mejor la atención del lector. Se ha constatado que el empleo de metáforas y de referencias literarias además de enriquecer el texto, lleva a cabo una función atenuadora del discurso. Asimismo, se ha detectado una estrategia novedosa para desinformar a los lectores a través del empleo del discurso literario como estrategia para confundir a la audiencia entre realidad y ficción. Además, al utilizar estos mecanismos expresivos queda implícita la intencionalidad del medio. Sin embargo, a pesar de que la cortesía es una estrategia conversacional no siempre logra o no siempre tiene el objetivo de evitar el conflicto.

El uso o el abuso de la teoría de la cortesía, empleado con frecuencia en la prensa sensacionalista, constituye una herramienta cada vez más utilizada en nuestros días en otros medios de comunicación. De manera análoga es posible considerar que, si este tipo de estrategias en publicidad se emplean para vender un producto, en los medios se utiliza para vender 
una información. Estaríamos, por tanto, ante el uso o abuso de la denominada descortesía de carácter estratégico por parte de la prensa. Si bien no nos encontramos ante un medio sensacionalista, sí hallamos recursos lingüísticos y de contenido que tienen el propósito de causar un cierto grado de sensacionalismo y de impacto en el lector, y, en consecuencia, en la imagen de la popularidad de la institución monárquica. La sensibilidad del receptor desempeña un papel fundamental en la interpretación de la información. Una explicación al empleo de los actos de amenaza a la imagen de España en The Guardian se pueda hallar en el hecho de que la tendencia general del lector es buscar en los medios de comunicación la confirmación de sus ideas, es decir, juzgando el objetivo de las fuentes de acuerdo con sus propias convicciones.

Este análisis ha confirmado el empleo de recursos estilísticos para incorporar sesgos sutiles en informaciones contrarias a la imagen de la monarquía.

A la vez, en este estudio se pone de manifiesto la posibilidad que tienen los medios de comunicación de mitigar expresiones demasiado explícitas que puedan generar un acto de amenaza contra la imagen pública de España, así como aquellos actos del habla en los que intencionadamente se lleva a cabo esta amenaza.

No podemos obviar los peligros de ofrecer información distorsionada o imprecisa, aún de un modo sutil y adornada con recursos literarios eficaces, puede tener consecuencias comunicativas y sociales sobre uno de los organismos fundamentales para la imagen de un país.

\section{Referencias bibliográficas}

Alcaide Lara, E.R. (2010). La descortesía (también) se vende: Acercamiento al estudio de las estrategias descorteses en el discurso publicitario. En F. Orletti y L. Mariottini (Eds.), La (des)cortesía en español. Espacios teóricos y metodológicos para su estudio (pp.221-244). Roma, Italia y Estocolmo, Suecia: Università Roma Tre/ Stockholm University.Programa Edice.

Alcoba, D. y Poch, S. (2011). Cortesía y publicidad. Barcelona: Ariel Letras.

Alonso Benito, L.E. (2014). El contexto sociopolítico de la crisis económica: límites institucionales y protesta social. Disponible en bit.ly/2ld1EDh

Austin, J. L. (1962). Cómo hacer cosas con palabras. Barcelona: Paidós.

Badillo, Á. (2019). La sociedad de la desinformación: propaganda, «fake news» y la nueva geopolítica de la información. Documento de trabajo 8/2019 - 14 de mayo de 2019 - Real Instituto Elcano.

Barredo Ibáñez, D. (2013). Siglo XXI y la monarquía. Propuestas para dinamizar la caracterización informativa del rey Juan Carlos I. Área Abierta. Vol.13. No 3. Noviembre 2013.

Brown, P., y Levinson, C. (1987) Politeness. Some Universals in Language Usage. Cambridge: Cambridge University Press. Burgueño, J.M. (2018). Fake news, un fenómeno nuevo con siglos de historia. Disponible en bit.ly/2kKza3g 
Cabrera González, E. y Ruiz San Román, J.A. (2007). Mentiras: Historias ciertas en medios con prestigio social. En A. Méndiz Noguero y C. Cristófol Rodríguez (Coords.), Falsedad y comunicación. Publicidad engañosa, Información falsa, Imagen manipulada (pp.113-119). Universidad de Málaga: Servicio de Publicaciones de la Universidad de Málaga.

Carrasco Santana, A. (1999). Revisión y evaluación del modelo de cortesía de Brown \& Levinson. Pragmalingüística, 7, (pp.1-44).

Casas Gómez, M. (1986): La interdicción lingüística. Mecanismos del eufemismo y del disfemismo. Cádiz: Publicaciones de la Universidad de Cádiz.

Díaz Pérez, J. C. (2012). Pragmalingüística del disfemismo y la descortesía: los actos de habla hostiles en los medios de comunicación virtual. Tesis doctoral. Universidad Carlos III de Madrid.

Fuentes Rodríguez, C. (2009). Descortesía y agresividad bajo el anonimato: Internet. En C. Fuentes Rodríguez y E. Alcaide Lara (Coords.), Manifestaciones textuales de la descortesía y agresividad verbal en diversos ámbitos comunicativos (pp. 188-208).Universidad Internacional de Andalucía.

García Inda, A. (2019). "Fakes”. El Heraldo. Disponible en bit.ly/2mO2ExP

Gil, J.A (2006). Amenaza e invasión de la imagen. Un estudio sobre la naturaleza de la cortesía verbal. Pragmalingüística, 14, 75-86. https://doi.org/10.25267/Pragmalinguistica.2017.i25

Goffman, E. (1967), Interactional ritual: essays on face to face behavior. Nueva York: Garden City.

Grice, H.P. (1975). Logic and Conversation. En Cole, P.; Morgan J. L. (Eds.), Syntax and Semantics, vol. 3: Speech Acts (pp. 41-58) Nueva York: New York Academic Press.

Hernández Corchete, S y Gómez Baceiredo, B. (2010) Fábula y argumentación como estrategia persuasiva en el discurso periodístico de opinión. En C. Martínez Pasamar (auto.), Estrategias argumentativas del discurso periodístico (pp. 51-68). Rétor, Vol. 2, No 1.

Lakoff, R. (1973). The Logic of Politeness or Minding your P’s and Q's. En Proceedings of the Ninth regional Meeting of the Chicago Linguistic Society, pp. 345-356.

Leech, G. (1983). Principles of pragmatics. Londres: Longman.

McCombs, M. (1994). The Future Agenda for Agenda-Setting Research.Journal of Mass Communication Studies, nº45, pp. 171-181.

Murado, M.A. (6 de abril de 2013). King Juan Carlos of Spain: a fairytale told by politicians. The Guardian. Disponible en bit.ly/2mltKMP

Rodríguez Cuadrado, B.(2017). Análisis sociolingüístico de la imagen de España e Italia en Theguardian.com (2013 -2014). Tesis doctoral. Universidad Complutense de Madrid, Madrid.

Rodríguez Cuadrado, B. (2019). Fake news: ¿Desuniendo la Unión Europea? En M.R. Czubala Ostapiuk (editor.), La UE: Claves y desafíos actuales del proyecto común. Madrid: Editorial Sindéresis. 
Sadovnikova M.N., Nevolnikova S.V., Bogatskaia E.Y. (2016). Euphemisms in language of the french mass media: pragmatical aspect. Russian linguistic bulletin. No3 (7), pp. 69-73.

Saz Rubio, M.M. (2000). La cortesía lingüística en el discurso publicitario. Valencia: SELL Universitat de Valencia.

Sullivan, E. (2003). El pequeño gran libro de la mentira, Barcelona: Paidós.

Watts, R. (2008). Rudeness, conceptual blending theory and relational work. Journal of Politeness Research, 4, 2, pp.289-317.

Vilarroya, Ó. (2019). Somos lo que contamos. Barcelona: Editorial Ariel.

Yus, F. (2010). Ciberpragmática 2.0. Nuevos usos el lenguaje en Internet. Barcelona: Editorial Ariel. 
